\title{
Establishing milestones in urology training: A survey of the Canadian Academy of Urological Surgeons
}

\author{
Madhur Nayan, ${ }^{*}$ Anne-Marie Houle, MD, FAAP, FRCSC, MBA; ${ }^{\dagger}$ Elspeth McDougall, MD, FRCSC, MHPE,; \\ Gerald M. Fried, MD, FRCSC, ${ }^{\ddagger}$ Sero Andonian, MD, MSc, FRCSC*
}

`Division of Urology, Department of Surgery, McGill University Health Centre, McGill University, Montreal, QC; 'Division of Pediatric Urology, Department of Surgery, Centre Hospitalier Universitaire SainteJustine, Université de Montreal, Montreal, QC; §Department of Urology, University of California, Irvine, Orange, CA; ‘Department of Surgery, McGill University Health Centre, McGill University, Montreal, QC

See related article on page 175 .

Cite as: Can Urol Assoc J 2012;6(3):168-74. http://dx.doi.org/10.5489/cuaj.11248

\section{Abstract}

Background: At the current time, technical skills are not directly evaluated by the Royal College of Physicians and Surgeons of Canada (RCPSC) as part of the certification process in urology. Rather, the RCPSC relies on the evaluation of Program Directors to ensure that trainees have acquired the necessary surgical skills. Methods: An electronic survey was sent out to the members of the Canadian Academy of Urological Surgeons (CAUS), including the 13 Canadian urology program directors, to assess the teaching and evaluation of technical skills of urology trainees.

Results: The response rate was 37\% (33/89), including 8 of the 13 (62\%) Program Directors from across Canada. For the teaching of technical skills, most programs had access to live animal laboratories $(69 \%)$, dedicated teaching time in simulation (59\%) and physical training models (59\%). Most relied on voluntary faculty. There was a wide variety of structured evaluations for technical skills used across programs, while $36 \%$ of respondents did not use structured evaluations. For trainees with deficiencies in technical skills, $67 \%$ of programs offered extra operative time with designated faculty, $26 \%$ offered additional simulation focused on the deficiency and $19 \%$ offered faculty tutorial sessions.

Conclusion: Among Canadian urology residency programs, there is considerable variability in the assessment of technical skills of trainees. Standardized objective assessment tools would help ensure that all trainees have acquired adequate surgical proficiency to operate independently.

\section{Introduction}

The Royal College of Physicians and Surgeons of Canada (RCPSC) is the governing body responsible for setting the standards for all Canadian urology residency training programs and the requirements trainees must fulfill to receive certification in urology. ${ }^{1,2}$ Currently, one of the require- ments of certification is that trainees successfully complete the examination set out by the RCPSC. ${ }^{3}$ This examination provides a good assessment of a trainee's knowledge base and level of medical expertise in urology. ${ }^{4}$ However, assessing whether trainees have acquired the necessary level of surgical technical proficiency during residency to go into independent practice is not part of the certification process. Rather, the RCPSC relies on Program Directors (PDs) to ensure that the "resident has acquired the competencies of the specialty/subspecialty as prescribed in the Objectives of Training and is competent to practice as a specialist." ${ }^{5}$

Recent studies have demonstrated that many graduating urology trainees have inadequate experience in some procedures, such as retroperitoneal lymphadenectomy and urinary diversions. ${ }^{6,7}$ Furthermore, the introduction of working-hour restrictions for trainees may decrease the opportunity for operative exposure of some of the less common urologic procedures. ${ }^{8}$ Finally, with the increasing use of roboticassisted laparoscopic surgery, trainees may not be receiving adequate training to allow them to independently perform Class A procedures as described by RCPSC. ${ }^{9}$ The RCPSC relies on the summative evaluation of the PDs to determine whether a trainee has acquired the necessary surgical skills during residency. The aim of the present study was to assess the methods used to teach technical skills, the tools used in the evaluation of technical skills of trainees, and the remedial work for trainees not meeting their training requirements.

\section{Methods}

An electronic survey was designed to assess how trainees are evaluated in Canadian urology training programs. The survey (Appendix 1) was sent to all 89 members of the Canadian Academy of Urological Surgeons (CAUS). The survey questions included whether:

- the respondent was a PD;

- a dedicated training curriculum was in place and the number of hours trainees spent in this curriculum; 
- a regular curriculum evaluation with trainees was performed;

- the American Urological Association (AUA) In-Service Examination was part of the yearly evaluation processs;

- a passing score was set for the AUA In-Service Examination and the remediation requirements for trainees who failed to meet the passing score;

- there were established methods of teaching technical skills;

- there were objective structured evaluations and remediation requirements for trainees who have an identified deficiency in surgical/operative skills; and

- technical skills should be evaluated as part of the RCPSC certification process.

To ensure confidentiality, responses were submitted anonymously. Fisher's exact test was used to compare the responses between PDs and non-PDs. A two-tailed $p$-value less than 0.05 was considered significant.

\section{Results}

The response rate was $37 \%(33 / 89)$, including 8 of the 13 $(62 \%)$ Program Directors from across Canada. Most respondents $(33 \%)$ had 15 or more trainees in their program, while $27 \%$ of respondents had 11 to $14,18 \%$ had 7 to $10,18 \%$ had 4 to 6 , and $3 \%$ had 3 or less trainees. Average duty hours for trainees ranged from less than 50 hours in $7 \%$ of respondents, 51 to 60 hours in 37\%, 61 to 70 hours in 33\%, 71 to 80 hours in $15 \%$, and over 80 hours in $7 \%$. Almost all of the respondents (96\%) reported having a dedicated urology training curriculum in place. The number of hours per week that residents spent in the curriculum varied; $8 \%$ of respondents reported 10 hours or more, $21 \%$ reported 6 to 9 hours, $63 \%$ reported 3 to 5 hours, $4 \%$ reported 2 hours, and $4 \%$ reported 1 hour. Most respondents (88\%) had regular curriculum evaluation by the residents. There were no significant differences in the responses from PDs and non-PDs $(p>0.05)$ (Table 1).

All of the respondents reported using the AUA In-Service Examination (AUA ISE) as part of the yearly trainee evaluation process. However, the score that was considered a pass differed across respondents; $3 \%$ of the respondents used above the $30^{\text {th }}$ percentile as a pass, $10 \%$ used above the $40^{\text {th }}$ percentile, $45 \%$ used above the $50^{\text {th }}$ percentile, $29 \%$ above the $60^{\text {th }}$ percentile, $3 \%$ used no passing score (Table 1). Three respondents did not indicate an answer. There were no significant differences among the answers from PDs and non-PDs (Table 1). Remediation requirements for trainees not meeting their respective pass requirement differed among respondents. Five of the eight $(62 \%)$ PDs used required reading, two did not have any remediation requirement, and one did not select an answer. On the other hand, non-PDs responded with the use of required reading
$(72 \%)$, faculty tutorials (60\%) and additional examinations $(40 \%)$, while $8 \%$ did not select an answer (Table 1 ).

With regards to the teaching of technical skills, $75 \%$ of the PDs used live animals, 50\% used physical training models and $25 \%$ used dedicated teaching time in the simulation centre. Only one PD reported using virtual reality. On the other hand, most non-PDs responded with dedicated teaching time in a simulation centre $(71 \%)$, live animal laboratory sessions $(67 \%)$ and physical training models $(62 \%)$. Other modalities less frequently used were virtual reality $(29 \%)$, ex-vivo animal preparations (21\%) and cadavers $(8 \%)$, while $17 \%$ of non-PDs did not answer (Fig. 1). Only $3 \%$ of all respondents reported using paid teaching assistants, while the remaining respondents relied on faculty members, of which $73 \%$ were not compensated for their teaching. Although most respondents reported using various methods for the structured evaluation of technical skills, $36 \%$ of all respondents did not have any such system in place (Fig. 2). Intra-operative surgical performance devices were only used in $27 \%$ of trainee evaluations. Finally, remediation requirements differed across respondents; most PDs employed extra operative time with designated faculty to improve a trainee's technical skills (Table 1). Half of all respondents felt that it would be important to have technical skills evaluated in the RCPSC certification process.

\section{Discussion}

RCPSC certification in urology requires the successful completion of five requirements (Table 2). ${ }^{3}$ Completion of these requirements ensures that graduating trainees have attained the necessary knowledge required to be a practicing urological surgeon. However, a formal evaluation of technical skills is not currently part of the RCPSC certification process. Rather, the RCPSC uses the Final In-Training Evaluation Report (FITER), an evaluation form based on the CanMEDS roles that is completed by PDs, to assess whether a graduating trainee has acquired the necessary procedural skills proficiency during their training. ${ }^{5}$ As part of the FITER, PDs evaluate trainees on a five-point scale (rarely meets, inconsistently meets, generally meets, sometimes meets and consistently meets) on their ability to perform various endoscopic, open and laparoscopic procedures. PDs have a crucial role to ensure that graduating trainees have achieved adequate proficiency in technical skills to qualify for certification. Considering this, a survey was sent to CAUS members to determine what methods were used to teach technical skills, how trainees were evaluated, and what the remediation requirements were for trainees who had not met the predetermined requirements for their level of training.

Although almost all $(96 \%)$ of the respondents had a dedicated urology curriculum in place, the number of hours that trainees spent per week in the curriculum differed sig- 
Nayan et al.

\begin{tabular}{|c|c|c|c|c|c|}
\hline Question & & PDs $(n=8)$ & Non-PDs ( $n=25$ ) & Total $(\mathbf{n}=\mathbf{3 3})$ & $p$ value \\
\hline \multirow[t]{5}{*}{ Average duty hours } & Less than 50 & $0 / 7(0 \%)$ & $2 / 20(10 \%)$ & $2 / 27(7 \%)$ & 0.955 \\
\hline & $51-60$ & $3 / 7(43 \%)$ & $7 / 20(35 \%)$ & $10 / 27(37 \%)$ & \\
\hline & $61-70$ & $2 / 7(29 \%)$ & $7 / 20(35 \%)$ & $9 / 27(33 \%)$ & \\
\hline & $71-80$ & $1 / 7(14 \%)$ & $3 / 20(15 \%)$ & $4 / 27(15 \%)$ & \\
\hline & More than 80 & $1 / 7(14 \%)$ & $1 / 20(5 \%)$ & $2 / 27(7 \%)$ & \\
\hline \multirow[t]{5}{*}{ Hours per week curriculum } & 1 & $1 / 7(14 \%)$ & $0 / 17(0 \%)$ & $1 / 24(4 \%)$ & 0.32 \\
\hline & 2 & $1 / 7(14 \%)$ & $0 / 17(0 \%)$ & $1 / 24(4 \%)$ & \\
\hline & $3-5$ & $4 / 7(57 \%)$ & $11 / 17(65 \%)$ & $15 / 24(63 \%)$ & \\
\hline & 6-9 & $1 / 7(14 \%)$ & $4 / 17(24 \%)$ & $5 / 24(21 \%)$ & \\
\hline & 10 or more & $0 / 7(0 \%)$ & $2 / 17(12 \%)$ & $2 / 24(8 \%)$ & \\
\hline \multirow[t]{5}{*}{ Passing score on AUA ISE } & $>30$ th percentile & $0 / 8(0 \%)$ & $1 / 23(4 \%)$ & $1 / 31(3 \%)$ & 0.066 \\
\hline & $>40$ th percentile & $2 / 8(25 \%)$ & $1 / 23(4 \%)$ & $3 / 31(10 \%)$ & \\
\hline & $>50$ th percentile & $3 / 8(37.5 \%)$ & $11 / 23(47 \%)$ & $14 / 31(45 \%)$ & \\
\hline & $>60$ th percentile & $0 / 8(0 \%)$ & $9 / 23(39 \%)$ & $9 / 31(29 \%)$ & \\
\hline & No passing score & $1 / 8(12.5 \%)$ & $0 / 23(0 \%)$ & $1 / 31(3 \%)$ & \\
\hline \multirow[t]{5}{*}{ Remediation for not passing AUA ISE } & Required reading & $5 / 8(62 \%)$ & $18 / 25(72 \%)$ & $23 / 33(70 \%)$ & 0.461 \\
\hline & Additional exams & $0 / 8(0 \%)$ & $10 / 25(40 \%)$ & $10 / 33(30 \%)$ & 0.035 \\
\hline & Faculty tutorials & $0 / 8(0 \%)$ & $15 / 25(60 \%)$ & $15 / 33(45 \%)$ & 0.003 \\
\hline & None & $2 / 8(25 \%)$ & $0 / 25(0 \%)$ & $2 / 33(6 \%)$ & 0.053 \\
\hline & No answer & $1 / 8(12.5 \%)$ & $2 / 25(8 \%)$ & $3 / 33(9 \%)$ & 0.44 \\
\hline \multirow[t]{4}{*}{ Remediation for not achieving technical skills } & Extra operative time & $5 / 7(71 \%)$ & $13 / 20(65 \%)$ & $18 / 27(67 \%)$ & 0.571 \\
\hline & Additional simulation training & $2 / 7(29 \%)$ & $5 / 20(25 \%)$ & $7 / 27(26 \%)$ & 0.367 \\
\hline & Faculty tutorial & $0 / 7(0 \%)$ & $5 / 20(25 \%)$ & $5 / 27(19 \%)$ & 0.192 \\
\hline & No answer & $1 / 7(14 \%)$ & $2 / 20(10 \%)$ & $3 / 27(11 \%)$ & 0.455 \\
\hline Skills assessment by RCPSC & Yes & $2 / 7(29 \%)$ & $11 / 19(58 \%)$ & $13 / 26(50 \%)$ & 0.378 \\
\hline
\end{tabular}

nificantly across programs. AUA In-Service examinations were used by all respondents and these scores have been shown to be a good predictor of performance on the RCPSC examination. ${ }^{10}$ However, the "passing score" and remediation requirements for those that did not pass differed across programs. The variability between programs is not surprising considering that the RCPSC does not have specific guidelines with regards to in-training assessments; therefore, PDs have developed their own curriculum within the requirements of the RCPSC (Table 2). Although the curricula may differ from program to program, they are all generally adequate to prepare residents for the RCPSC examination, considering that most Canadian graduating trainees have successfully completed this certifying requirement over the past years.

In addition to teaching trainees the knowledge required for clinical practice, the development of technical skills is one of the basic tenets of any surgical training program. The traditional method of learning to perform procedures in the operating room has transitioned for the most part to learning and practicing procedures on various simulators and training models before applying the skills clinically. This allows trainees to learn in a non-stressful environment, practice skills repeatedly and focus on particular perfor- mance deficiencies to acquire acceptable, predetermined proficiency, away from the patient thereby reducing the risk of potential complications in clinical practice. ${ }^{11}$ The results of our survey demonstrate that most trainees are taught procedural skills through simulation centres, live animals and physical training models. It is reassuring that most respondents report the use of training models, as studies have consistently shown that skills training significantly improves trainee operative time and reduces complication rates. ${ }^{12-14} \mathrm{~A}$ year-round surgical skills curriculum was recently developed at the Southern Illinois University's Division of Urology in response to the introduction of the Accreditation Council on Graduate Medical Education's competency curriculum, which requires the implementation of measurable teaching methods in technical skills training..$^{15} \mathrm{~A}$ survey of the participants in the training sessions showed a high degree of satisfaction; moreover, an incremental progression in proficiency was observed by the instructors and the participants. It is important to note that when teaching a new technical skill, it has been shown that trainees have significantly better retention and transfer of skills when they are taught consistently over time, rather than longer but less frequent sessions. ${ }^{16} \mathrm{On}$ the other hand, Stefanidis and colleagues described some 
challenges that came up during the implementation of a laparoscopic skills curriculum in a general surgery training program. ${ }^{17}$ They found that while there was initial enthusiasm about the curriculum from residents, the attendance rates decreased quickly. This was thought to have been mostly due to the lack of supervising personnel and protected training time. With the hiring of a dedicated skills laboratory coordinator and assigning dedicated time for skills training, attendance increased dramatically. The present survey revealed that only $3 \%$ of respondents reported the use of paid teaching assistants, while the remaining respondents consistently relied on voluntary faculty members who were not compensated for their teaching. It would be interesting to see what proportion of residents participated regularly in skills training considering that their supervision may not be optimal without a paid dedicated skills laboratory coordinator and that they may not have adequate dedicated time for skills training, with $55 \%$ of respondents reporting at least 60 hours of duty per week. This was not assessed in this survey.

The practice of technical skills on a training model will help a trainee improve their technical skills. However, ultimately, their ability to operate on live patients will determine if they are capable of operating without supervision. Since studies have correlated patient outcomes with surgeon volume, ${ }^{18,19}$ it is reasonable to assess if trainees are receiving adequate surgical exposure during residency. A study by Chang and colleagues demonstrated that while in some training programs trainees have adequate experience with urinary diversions, over $50 \%$ of graduating trainees performed less than 6 continent diversions. ${ }^{7}$ The same group also found that half of the graduating trainees had performed
Table 2. Royal College of Physicians and Surgeons of Canada certification requirements in urology

1. Successful completion of a two year Royal College Surgical Foundations curriculum

2. Successful completion of the Royal College Principles of Surgery examination

3. Successful completion of a five year Royal College accredited program in urology

4. Successful completion of at least one scholarly project related to urology, as attested by the Program Director

5. Successful completion of the Royal College examination in urology

Adapted from the RCPSC. ${ }^{3}$

less than 3 retroperitoneal lymph node dissections as the primary surgeon or the first assistant. Although it is certainly difficult to define the number of procedures required for a resident to be considered competent, the consequences of inadequate training may negatively affect patient outcome. Since the RCPSC does not formally evaluate technical skills, it is the responsibility of PDs to determine if a graduating trainee is capable of operating independently. The present survey reveals that while most programs have some method of evaluating technical skills, $36 \%$ of respondents report no such structured evaluation. The common evaluation methods were simulation centre performance assessment in surgical skills, checklists, intra-operative assessments and global rating scales. In comparison, a survey of otolaryngology training PDs in the United States found that most respondents used the Objective Structured Assessment of Technical Skills (OSATS) and virtual reality to evaluate surgical skills competency. ${ }^{20}$ That survey, however, did not report

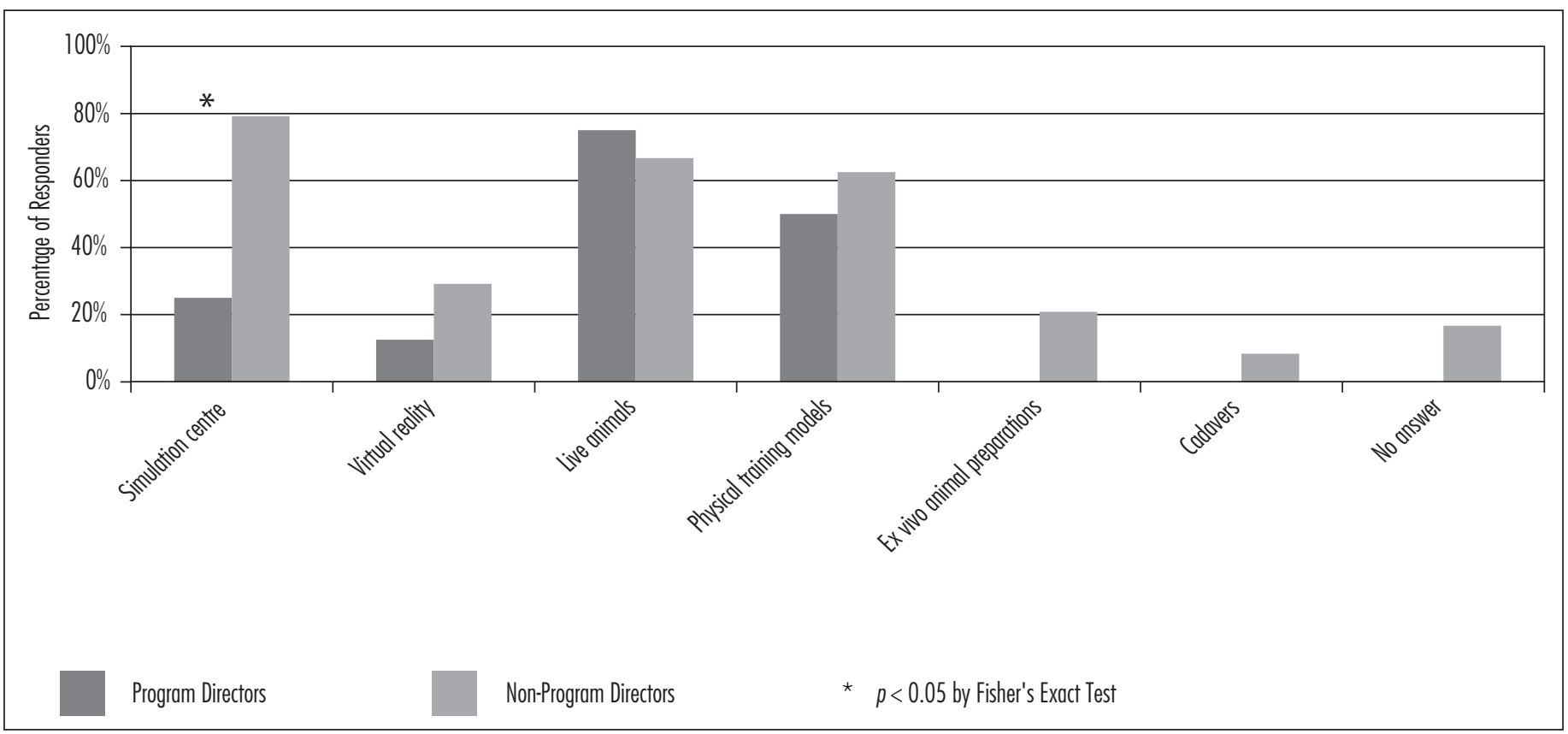

Fig. 1. Teaching of technical skills. 
Nayan et al.

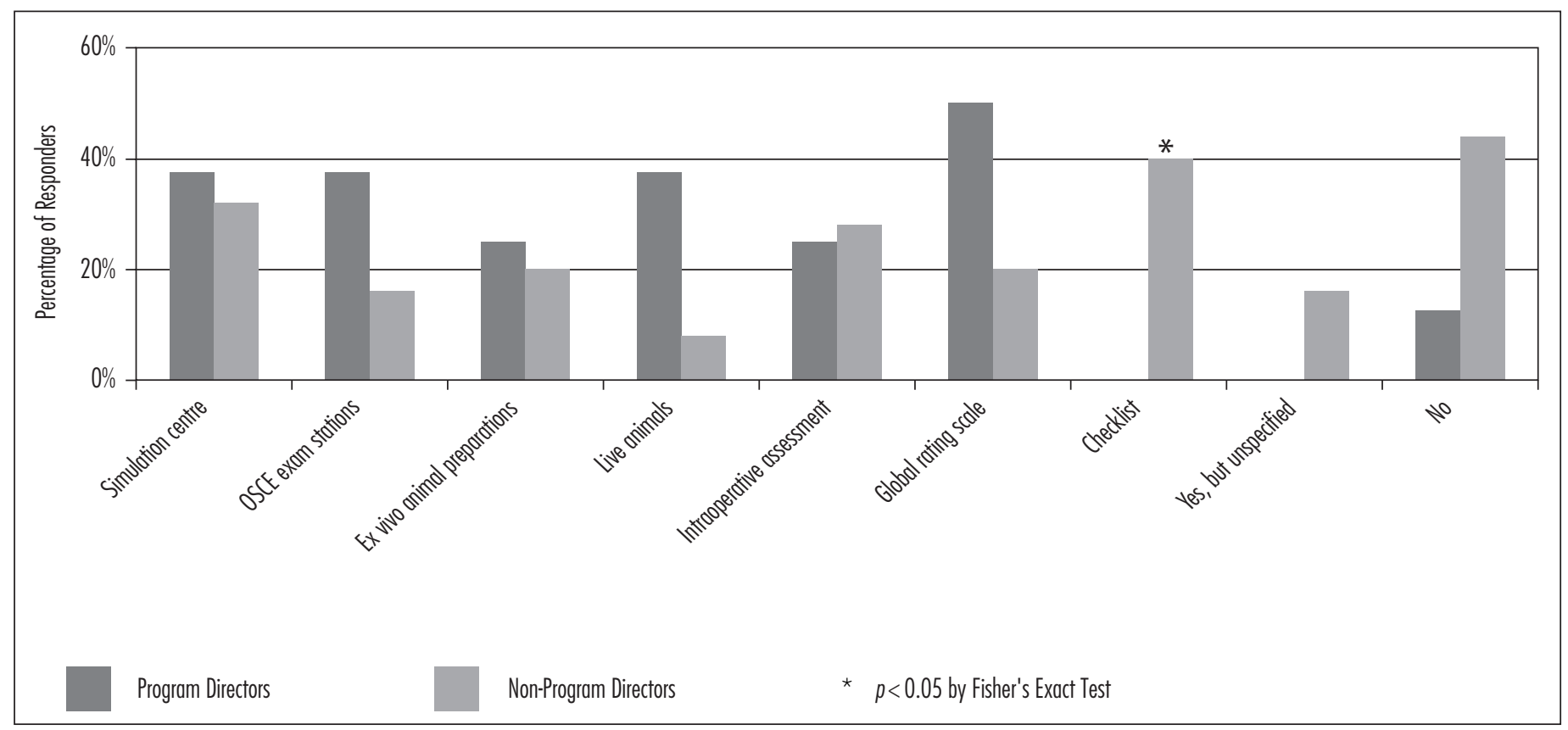

Fig. 2. Structured evaluation of technical skills.

the number of respondents that did not use any objective assessment tool. With objective evaluations, instructors are able to aid in learning through directed constructive feedback, determine the proficiency level that the trainee has reached, and ensure that progress is being appropriately achieved for each trainee. However, it is not known if the evaluation methods being used currently by survey respondents have been validated for their designated use. For trainees not reaching the appropriate predetermined skills milestone, the present survey reveals that extra operative time with designated faculty will be used by respondents to help bring a trainee's surgical skills up to an acceptable level of proficiency.

Surgical education has shifted towards being more competence-based. This paradigm shift is illustrated by that fact that certification by the American Board of Surgery (ABS) now requires successful completion of the Fundamentals of Laparoscopic Surgery (FLS). FLS, which is based on the McGill Inanimate System for Training and Evaluation of Laparoscopic Skills (MISTELS), has been extensively validated and has been shown to correlate highly with laparoscopic skills as measured in the operating room. As such, FLS could potentially be used by urology training programs to objectively evaluate basic laparoscopic skills. ${ }^{21,22}$ While the RCPSC does not currently evaluate technical skills as part of the certification process, it is possible that they may do so in the future and half of the respondents of the present survey would support this change. If this were to occur, training programs would be much better prepared to ensure the success of their graduating residents if they were able to demonstrate a trainee's technical proficiency through objec- tive assessment tools already in place. At the present time, validated assessment tools in urology only exist for endourological skills. ${ }^{23,24}$ Improving urology training and ensuring that all trainees acquire adequate surgical proficiency will require the further development of validated objective methods of evaluation, as has been done in other surgical fields, ${ }^{25-29}$ and implementing these in training programs across Canada.

Although the present study is limited by a low response rate of $37 \%$, most PDs were included. Furthermore, this response rate is comparable to that of other surveys of PDs, where the response rates varied between $27 \%$ and $42 \% .{ }^{30,31}$ In addition, the small sample size may not have allowed differences between PDs and non-PDs to be detected (Type II error). Furthermore, it may be possible that some training programs may be over- or under-represented. However, to ensure anonymity of responses, there were no identifying features in the survey thereby making it impossible to differentiate training programs.

\section{Conclusion}

The current certification process from the RCPSC does not include a formal evaluation of technical skills. Instead, formal evaluation is the responsibility of PDs. They must ensure that graduating trainees have reached a level of technical proficiency that is adequate to operate without supervision. A survey of CAUS members demonstrated that there is considerable variability between the different training programs, with $36 \%$ of respondents reporting no structured evaluation method in place. The development and implementation of 
validated objective methods of evaluation will ensure that all graduating trainees in urology receive adequate surgical training for independent practice.

\section{Competing interests: None declared.}

This paper has been peer-reviewed.

\section{References}

1. Royal College of Physicians and Surgeons of Canada. Specific Standards of Accreditation for Residency Programs in Urology; 2010. http://rrpsc.medical.org/residency/accreditation/ssas/urolog_e.pdf (Accessed May 1, 2012).

2. Royal College of Physicians and Surgeons of Canada. Objectives of Training in Urology; 2009. http:// rcpsc.medical.org/residency/_ertification/objectives/urology_e.pdf (Accessed May 1, 2012).

3. Royal College of Physicians and Surgeons of Canada. Specialty Training Requirements in Urology; 2011. hittp://rrpsc.medical.org/residency/Cerrification/training/urology_e.pdf (Accessed May 1, 2012).

4. Royal College of Physicians and Surgeons of Canada. Format of the Comprehensive Objective Examination in Urology. httrp://rcpsc.medicalorg/residency/certification/examformats/360_e.php (Accessed May 1, 2012).

5. Royal College of Physicians and Surgeons of Canada. Final in-Training Evaluation Report (FITER)/ Comprehensive Competency Report (CCR); 2009. http://rcpsc.medical.org/residency/certification/ fiters/urology_e.pdf (Accessed May 1, 2012).

6. Lowrance WT, Cookson MS, Clark PE, et al. Assessing retroperitoneal lymphadenectomy experience in United States urological residency programs. I Urol 2007;178:500-3; discussion 503.

7. Chang SS, Smith JA Jr, Herrell SD, et al. Assessing urinary diversion experience in urologic residency programs-are we adequately training the next generation? I Urol 2006;176:691-3.

8. Jarman BT, Miller MR, Brown RS, et al. The 80-hour work week: will we have less-experienced graduating surgeons? Curr Surg 2004;61:612-5.

9. Mamut AE, Afshar K, Mickelson JJ, et al. Surgical case volume in Canadian urology residency: a comparison of trends in open and minimally invasive surgical experience. J Endourol 2011;25:1063-7. http://dx.doi. org/10.1089/end.2010.0304

10. Baverstock RJ, MacNeily AE, Cole G. The American Urological Association In-Service Examination: performance correlates with Canadian and American specialty examinations. J Urol 2003;170:527-9. http:// dx.doi.org/10.1097/01.ju.0000081598.38024.d2

11. Ziv A, Wolpe PR, Small SD, et al. Simulation-based medical education: an ethical imperative. Acad Med 2003;78:783-8.

12. Seymour NE, Gallagher $A G$, Roman $S A$, et al. Virtual reality training improves operating room performance: results of a randomized, double-blinded study. Ann Surg 2002;236:458-63; discussion 463-4.

13. Schijven MP, Jakimowicz JJ, Broeders IA, et al. The Eindhoven laparoscopic cholecystectomy training course-improving operating room performance using virtual reality training: results from the first E.A.E.S. accredited virtual reality trainings curriculum. Surg Endosc 2005;19:1220-6. http://dx.doi. org/10.1007/s00464-004-2240-1

14. Kallstrom R, Hjertberg H, Svanvik J. Impact of virtual reality-simulated training on urology residents' performance of transurethral resection of the prostate. J Endourol 2010;24:1521-8.
15. Hammond L, Ketchum J, Schwartz BF. Accreditation council on graduate medical education technical skills competency compliance: urologic surgical skills. J Am Coll Surg 2005;201:454-7. http://dx.doi. org/10.1016/i.jamcollsurg.2005.05.002

16. Moulton CA, Dubrowski A, Macrae H, et al. Teaching surgical skills: what kind of practice makes perfect? a randomized, controlled trial. Ann Surg 2006;244:400-9.

17. Stefanidis D, Acker CE, Swiderski D, et al. Challenges during the implementation of a laparoscopic skills curriculum in a busy general surgery residency program. J Surg Educ 2008;65:4-7. http://dx.doi. org/10.1016/i.jurg.2007.11.009

18. Birkmeyer JD, Stukel TA, Siewers AE, et al. Surgeon volume and operative mortality in the United States. N Engl J Med 2003;349:2117-27.

19. Goossens-Laan CA, Gooiker GA, van Gijn W, et al. A systematic review and meta-analysis of the relationship between hospital/surgeon volume and outcome for radical cystectomy: an update for the ongoing debate. Eur Urol 2011;59:775-83.

20. Brown DJ, Thompson RE, Bhatti NI. Assessment of operative competency in otolaryngology residency: Survey of US Program Directors. Laryngoscope 2008;118:1761-4. http://dx.doi.org/10.1097/ MLG.0b013e31817e2c62

21. Sroka G, Feldman $L S$, Vassiliou MC, et al. Fundamentals of laparoscopic surgery simulator training to proficiency improves laparoscopic performance in the operating room-a randomized controlled trial. Am J Surg 2010;199:115-20.

22. Vassiliou MC, Dunkin BJ, Marks JM, et al. FLS and FES: comprehensive models of training and assessment. Surg Clin North Am 2010;90:535-58.

23. Matsumoto ED, Hamstra SJ, Radomski SB, et al. A novel approach to endourological training: training at the Surgical Skills Center. J Urol 2001;166:1261-6.

24. Matsumoto ED, Pace KT, Honey RJ. Virtual reality ureteroscopy simulator as a valid tool for assessing endourological skills. Int J Urol 2006; 13:896-901. http://dx.doi.org/10.1111/i.1442-2042.2006.01436.x

25. Van Heest A, Putnam $M$, Agel J, et al. Assessment of technical skills of orthopaedic surgery residents performing open carpal tunnel release surgery. J Bone Joint Surg Am 2009;91:2811-7.

26. Insel $A$, Carofino $B$, Leger $R$, et al. The development of an objective model to assess arthroscopic performance. J Bone Joint Surg Am 2009;91:2287-95.

27. Ezra DG, Aggarwal R, Michaelides $M$, et al. Skills acquisition and assessment after a microsurgical skills course for ophthalmology residents. Ophthalmology 2009;116:257-62.

28. Woodrow SI, Dubrowski A, Khokhotva M, et al. Training and evaluating spinal surgeons: the development of novel performance measures. Spine (Phila Pa 1976) 2007;32:2921-5.

29. Zirkle $M$, Roberson DW, Leuwer $R$, et al. Using a virtual reality temporal bone simulator to assess otolaryngology trainees. Laryngoscope 2007;117:258-63. http://dx.doi.org/10.1097/01. mlg.0000248246.09498.b4

30. Mir HR, Cannada LK, Murray IN, et al. Orthopaedic resident and program director opinions of resident duty hours: a national survey. J Bone Joint Surg Am 2011;93:e1421-9.

31. Duchene DA, Moinzadeh A, Gill IS, et al. Survey of residency training in laparoscopic and robotic surgery. J Urol 2006;176:2158-66; discussion 2167.

Correspondence: Dr. Sero Andonian, Assistant Professor of Urology, Royal Victoria Hospital, McGill University Health Centre, 687 avenue des Pins Ouest, Suite S6.92, Montreal, QC H3A 1A1; fax: 514-843-1552; sero.andonian@muhc.mcgill.ca 
Nayan et al.

\section{Appendix 1. Survey}

\section{Part 1}

1. I am a program director

a. Yes

b. No

\section{Part 2}

1. What remediation do you provide for a resident who is identified as having a deficiency in surgical/operative skills?

a. Extra operative time with designated faculty

b. Additional simulation training specifically focused on the technique or procedure of identified deficiency c. Faculty tutorial sessions related to operative deficiency

2. How many residents do you have in your training program?

a. 1-3

b. $4-6$

c. $7-10$

d. $11-14$

e. 15 or more

3. Do you utilize the In Service Examination as part of your yearly resident evaluation process?

a. Yes

b. No

4. What do you use as the "passing score" you expect the residents in your program to achieve on the ISE?

a. $>30$ th percentile

b. $>40$ th percentile

c. $>50$ th percentile

d. $>60$ th percentile 2. What are the average duty hours for the residents in your urology training program?

a. Less than $50 \mathrm{~h}$

b. $51-60 \mathrm{~h}$

c. $61-70 \mathrm{~h}$

d. $71-80 \mathrm{~h}$

e. More than $80 \mathrm{~h}$

3. Do you have a dedicated urology training curriculum in place at your institution?

a. Yes

b. No

4. How many hours per week do the residents spend in this curriculum?

a. $1 \mathrm{~h}$

b. $2 \mathrm{~h}$

c. $3-5 h$

d. $6-9 \mathrm{~h}$

e. $10 \mathrm{~h}$ or more

5. What remediation do you enlist for residents who do not "pass" the ISE?

5. Do you do regular curriculum evaluation with your residents?

a. Required reading

a. Yes

b. Additional examinations

b. No

c. Faculty tutorials in the area of deficiency

6. Do you have a structured approach to evaluating residents' technical skills?

a. Yes, but unspecified

b. In simulation centre

c. By OSCE exam stations

d. Using ex vivo animal preparations

e. Using live animals

f. Using structured intraoperative assessment

g. Global rating scale

h. Checklist

i. No

7. How do you teach technical skills?

a. Dedicated teaching time in simulation centre

b. Virtual reality

c. Live animals

d. Physical training models

e. Ex-vivo animal preparations

f. Cadavers

8. Who participates in skills training?

a. Voluntary faculty members

b. Paid teaching assistant

9. Faculty are compensated for teaching?

a. Yes

b. No

10. Do you use an intra-operative assessment device for resident

evaluation?

a. Yes

b. No

6. Do you think that technical skills evaluation should be part of the Royal College certification process?

a. Yes

b. No 